\title{
Modeling and evaluation of a threshing drum under vertical vibration
}

\author{
A. Syuhri*, I. Sholahuddin, S.N.H. Syuhri and R.D.H. Qoryah \\ Department of Mechanical Engineering, University of Jember \\ Jember, Indonesia \\ *Email: ahmad.syuhri@unej.ac.id
}

\begin{abstract}
A threshing drum in a power thresher has a main function for separating seeds from stems via threshing teeth. This part undergoes with high exposure of vibrations, which has a greater chance to work improperly and experiences a fatigue failure that can reduce the efficiency. The main objective of this paper is to obtain vibration characteristics of the proposed design of the threshing drum. In order to achieve the objective, the threshing drum is to be modeled as an equivalent spring and a mass, which is coupled in series mode with equivalent springs and dampers generated from bearings. The mathematical models of the system are derived only in vertical direction. The transfer function approach is established to obtain time and frequency domain analysis. Force and displacement transmissibility are plotted in the wide range of frequencies to perform transmitted force to the main frame, while vertical vibration exposures are evaluated based on ISO 2372. The result shows that the threshing drum design is in the good criterion that means the Root Means Square of the velocity lying from $0.11 \mathrm{~m} / \mathrm{s}$ to $2.8 \mathrm{~m} / \mathrm{s}$ taken from vibration severity index in the range of $400 \mathrm{rpm}$ to $1000 \mathrm{rpm}$.
\end{abstract}

Keywords: Threshing drum; stability analysis; transmissibility; vertical vibration; dynamics behavior.

\section{INTRODUCTION}

Vibration in rotating machinery has been of interest by many researchers. The root cause of this problem is imbalance mass where the center mass is either displaced or asymmetry from the axis of rotation [1]. This can be governed from internal and external factors. Internal factors are determined by material defects and material properties such as non-uniformity of material density and reliability of material; whereas external factors are influenced by manufacturing imprecision, degree of machining tolerances, bad positioning and loss of material resulted from friction [2]. When an imbalance mass occurs in rotating equipment, a centrifugal force will be altered as vibration exciter to the system that is usually lead to an unacceptable level of vibration [3]. The effects of imbalance mass in a rotor are affected in reducing lifetime of the bearing and increasing fatigue failure of the shaft under constant exposure of vibration. In other words, it closes to decrease a whole efficiency of a machine as part turn to wear out [4].

In the case of power thresher machine, the rotating components, considered as a source of vibration, are classified in three important sections such as in engine, belt transmission and threshing part [5]. Vibration in reciprocating engine has been widely studied by applying vibration isolation, for instance, a passive engine mount in most 
practical way that composed of a spring and, sometimes, a damper in order to suppress vibration [6,7]. The belt transmission was reported to inducing vibration caused by stiffness itself [8-10]. However, the belt vibration, in this configuration, depends on the behavior of the threshing unit as the output of the motion transmission. On the other hand, the threshing unit, installed by means of attaching a threshing wheel in a shaft, has a complex shape and contained of eccentricities, which are resulted in producing centrifugal force to incite vibration [11]. Moreover, the threshing unit is fully subjected with impact loads when stems are inserted into the machine.

In accordance to those problems, the aims of this paper are to analyze and to evaluate the proposed design of the threshing drum as the fundamental part in the threshing unit. The main contributions are (1) to propose some mathematical models associated with the threshing drum; and (2) to study vibration generated in a particular frequency ranges. To achieve these objectives, the following will be carried out: (1) structural design of the power thresher and dynamics modeling of the threshing drum; (2) transfer function analysis in frequency domain and time domain (zero state responses); and (3) transmissibility analysis and vibration severity index regarding ISO 2372 .

\section{DESIGN AND MODELLING}

The power thresher is generally configured by a main frame, a prime driver, a transmission and a threshing unit as shown in Figure 1. Here we use an engine as the prime mover rather than an electric motor for a mobility purpose and lack of access to electricity. It drives both the main shaft of the threshing drum and the fan by belt and pulley system as the transmission unit. The threshing unit mainly consists of a cover, a threshing drum, a separation plate and a fan. The threshing drum is formed by a cylinder with threshing teeth to pull off the seeds, which is attached by a main shaft and supported by two main bearings. The separation plate is designed with small holes as a hopper and filtering seeds from stems, while the cover is functioned to prevent seeds and stems from scattered.

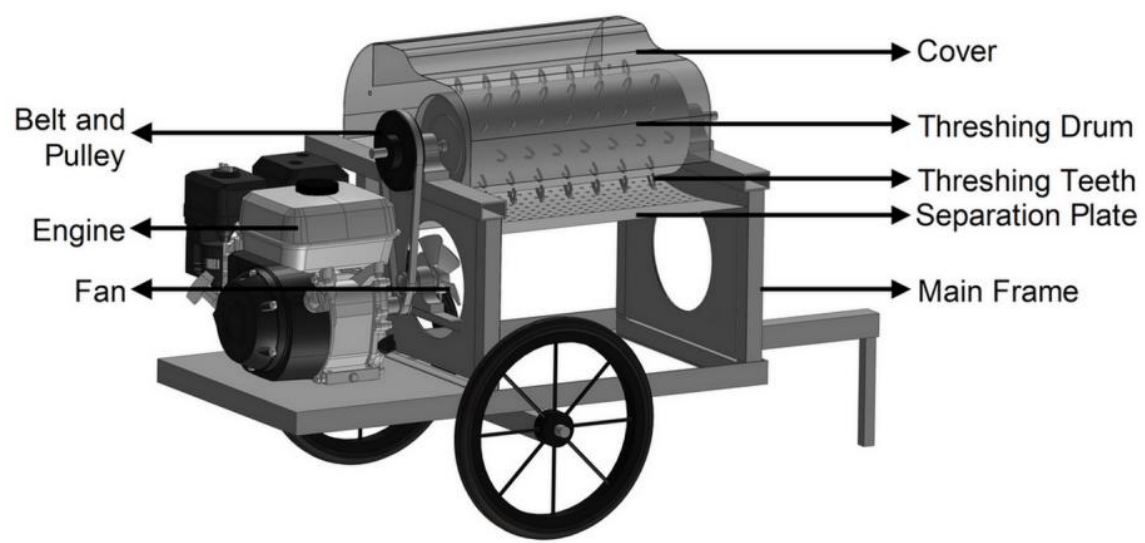

Figure 1. Proposed design of the power thresher.

As aforementioned, threshing drum is connected to the shaft which is supported by two main bearings. Based on Zeillinger \& Köttritsch [12], a bearing can be modeled as a spring $\left(K_{B}\right)$ and a damper $\left(C_{B}\right)$ with neglected mass, while the threshing drum is substituted with half of total mass worked in the shaft as shown in Figure 2(a). The main shaft itself is to be considered as a spring and denoted with $K_{E Q}$. Hence, the total 
physical system can be derived as a series connection between the bearings and the main shaft as shown in Figure 2(b).

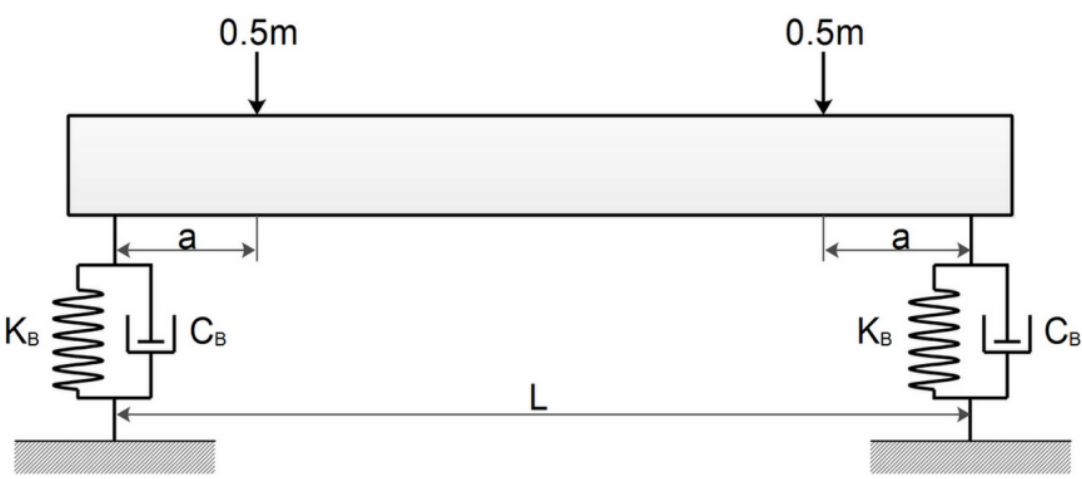

(a)

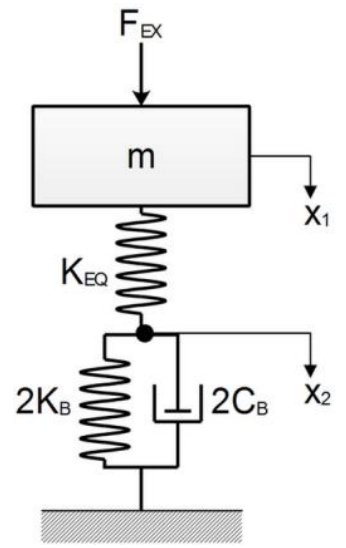

(b)

Figure 2. A physical system of (a) the main shaft subjected with load and bearing equivalents, (b) the total configuration model.

Using Newton's second law of motion that can be seen in [13], the free body diagram of Figure 2(b) can be written as follows,

$$
\begin{gathered}
M \ddot{x}_{1}+K_{E Q}\left(x_{1}-x_{2}\right)=F_{E X} \\
2 C_{B} \dot{x}_{2}+2 K_{B} x_{2}-K_{E Q}\left(x_{1}-x_{2}\right)=0
\end{gathered}
$$

where $K_{E Q}$ and $F_{E X}$ are the equivalent spring constant of the shaft and the excitation force derived from radial forces, respectively. Thus, the equations can be therefore given as follows [14],

$$
\begin{aligned}
& K_{E Q}=\frac{24 E I}{a\left(4 a^{2}-3 L^{2}\right)} \\
& F_{E X}=M r \omega^{2} \sin (\theta)
\end{aligned}
$$

where $E$ and $I$ represent modulus of elasticity and the moment of inertia of the rod respectively, $a$ and $L$ signify the length from the bearing support to the load and the total length of the rod respectively, $M$ and $r$ are the mass and the radius of the threshing drum respectively, and $\theta$ and $\omega$ denote the angular rotation and the angular velocity of the threshing drum.

In this model, we use ASTM-A36 (structural steel) as material, which has modulus of elasticity of $E=200.10^{9} \mathrm{~N} / \mathrm{m}^{2}$. The shaft has a diameter of $d_{\text {rod }}=0.02 \mathrm{~m}$ and a length of $L=0.65 \mathrm{~m}$ which produces a moment of inertia of $I=8.015 \times 10^{-5} \mathrm{~kg} . \mathrm{m}^{2}$. By means of careful drawing, the threshing drum has a total mass of $M=4.3013 \mathrm{~kg}$ including threshing teeth and a radius of $0.0885 \mathrm{~m}$, whereas the space between the bearing and the end of the threshing drum is $a=0.1 \mathrm{~m}$. In addition, the bearing properties such as $K_{B}$ and $C_{B}$ are determined by Zeillinger \& Köttritsch [12] based on the load about $0.6 \times 10^{8} \mathrm{~N} / \mathrm{m}$ and $400 \mathrm{~N} . \mathrm{s} / \mathrm{m}$, respectively. 


\section{RESULTS AND DISCUSSION}

Two analyses were carried out in this section to examine mathematical models of the system. The first analysis considers dynamics behavior of the system involving displacement, velocity and acceleration with regard to time and frequency domain while the second analysis computes force and displacement transmissibility in frequency series.

\section{Dynamics Behavior}

In order to conduct numerical analyses, the transfer function must be derived at first. By taking the Laplace transform [15] from Equations (1) and (2), with all the element values equal to unity and with $\mathscr{L}\left[F_{E X}(t)\right]=F_{E X}(s)$ which yields,

$$
\begin{aligned}
& {\left[M s^{2} X_{1}(s)-s x_{1}(0)-\dot{x}_{1}(0)\right]+K_{E Q} X_{1}(s)-K_{E Q} X_{2}(s)=F_{E X}(s)} \\
& {\left[2 C_{B} s X_{2}(s)-x_{2}(0)\right]+\left(2 K_{B}+K_{E Q}\right) X_{2}(s)-K_{E Q} X_{l}(s)=0}
\end{aligned}
$$

By assuming zero initial conditions and considering the output system as displacement in point $1\left(X_{1}\right)$ and point $2\left(X_{2}\right)$, the transfer function can be therefore given as follows,

$$
\begin{array}{lll}
G_{1}(s)=\frac{X_{1}(s)}{F_{E X}(s)}=\frac{2 C_{B} s+\left(2 K_{B}+K_{E Q}\right)}{2 M C_{B} s^{3}+\left(2 K_{B}+K_{E Q}\right) M s^{2}+2 K_{E Q} C_{B} s+2 K_{E Q} K_{B}} & {\left[\frac{m}{N}\right]} \\
G_{2}(s)=\frac{X_{2}(s)}{F_{E X}(s)}=\frac{K_{E Q}}{2 M C_{B} s^{3}+\left(2 K_{B}+K_{E Q}\right) M s^{2}+2 K_{E Q} C_{B} s+2 K_{E Q} K_{B}} & {\left[\frac{m}{N}\right]}
\end{array}
$$

From the pole-zero map, we obtain that there are 3 pole and 1 zero in the Equation (5) or system $G_{l}(s)$ illustrated in Figure 3(a), where two poles are located in imaginary axis and the other is located in the same place with zero in the left side. It means that the system is marginally stable but indefinitely oscillates while approaching the steady-state level [16]. Although the pole values in system $G_{2}(s)$, resulted from the same denominator, are identical with system $G_{l}(s)$, there is no zero in this case based on Equation (6).

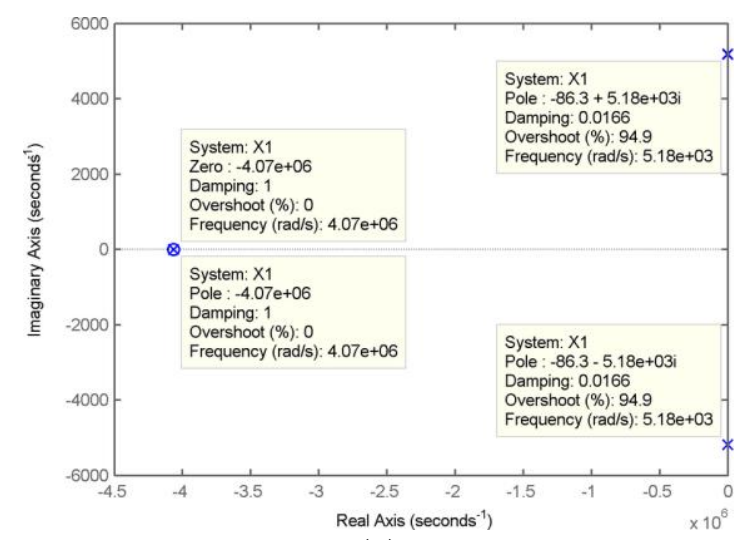

(a)

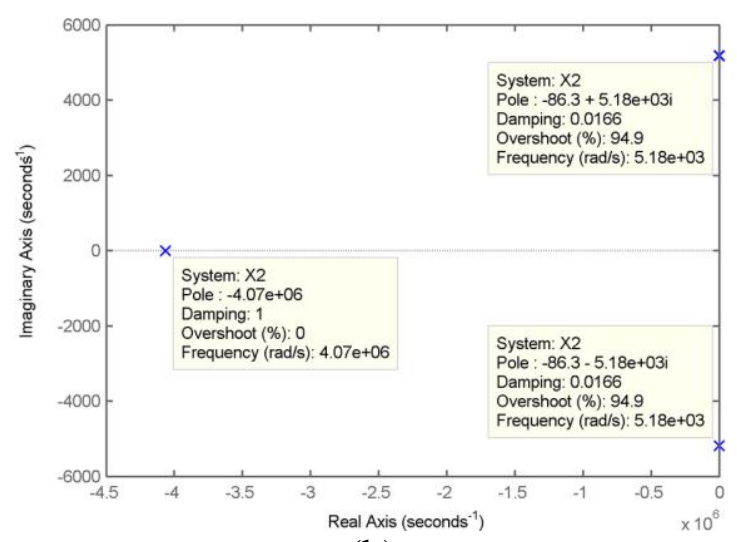

(b)

Figure 3. Pole-zero map of (a) System $G_{l}(s)$, (b) System $G_{2}(s)$.

To give the best explanation regarding those phenomena, the zero-state responses such as step response and impulse response are then demonstrated in Figures 
4(a)-(c) for displacement, velocity and acceleration, respectively. The velocity and acceleration are obtained by means of taking first and second time-derivative, respectively, of both Equations (7) and (8). Generally, there are no significant differences in between system $G_{1}(s)$ and $G_{2}(s)$, except with impulse response of acceleration.

These phenomena can be associated with Equations. (7) and (8), where the absences of the damping and stiffness in the bearing are not significant enough to influence the system [17]. Also, the stiffness equivalent of the rod is higher ten times compared with stiffness in the bearing. Thus, the peak amplitudes of step response are averagely at $1.62 \times 10^{-8} \mathrm{~m}, 4.21 \times 10^{-5} \mathrm{~m} / \mathrm{s}$ and $0.232 \mathrm{~m} / \mathrm{s}^{2}$ for displacement, velocity and acceleration, respectively for both systems. In the case of impulse response, the peaks of displacement and velocity are evenly gained at $4.21 \times 10-5 \mathrm{~m}$ and $0.224 \mathrm{~m} / \mathrm{s}$, respectively. On the contrary, the peaks of acceleration amplitude are obviously different with the value lies on $-1.18 \times 10^{3} \mathrm{~m} / \mathrm{s}^{2}$ and $9.11 \times 10^{5} \mathrm{~m} / \mathrm{s}^{2}$ in time of 0.000295 $s$ and $0 s$ for system $G_{l}(s)$ and $G_{2}(s)$, respectively. This can be caused by the second time-derivate of the systems that produced zero value in the pole-zero maps.

Figure 4(d)-(f) show the frequency response of the system in displacement, velocity, and acceleration, respectively. Mostly, there are no notable differences on the system $G_{l}(s)$ and $G_{2}(s)$, while the natural frequency is achieved at $5183.62 \mathrm{rad} / \mathrm{s}$ resulted from spring series connection. It can be related to the free body diagram shown in Figure 2(b) where the series connection produces mass-less in the equation of motion of $x_{2}$ appeared in Equation (2) in which the natural frequency is only affected by the total mass of the threshing drum. The peaks of displacement, velocity and acceleration amplitude yield averagely at $2.5 \times 10^{-7} \mathrm{~m}, 0.0013 \mathrm{~m} / \mathrm{s}$ and $6.8 \mathrm{~m} / \mathrm{s}^{2}$, respectively. At the same time, the phase angle is obtained at $-89.1 \mathrm{deg}, 0.881 \mathrm{deg}$ and $90.9 \mathrm{deg}$ for displacement, velocity and acceleration, respectively.

Based on the characteristics of threshing a plant, if the speed is set at higher than the upper bound, the grain will be crumbled. Otherwise, under the lower bound will produce insufficient force to remove the grains from the stems. From those reasons, the threshing drum will be set to work at low frequency in the range of $100 \mathrm{rpm}(10.5 \mathrm{rad} / \mathrm{s})$ to $1000 \mathrm{rpm}(104.7 \mathrm{rad} / \mathrm{s})$.

By taking reference from the threshing drum, represented with system $G_{l}(s)$, the displacement response of frequency domain is considerably small and constant with the magnitude value of $8.66 \times 10^{-9} \mathrm{~m}$ and phase angle drops in the small proportion from 0 $\mathrm{deg}$ to $-0.0382 \mathrm{deg}$. In the velocity response, the magnitude increases from initial condition to $8.97 \times 10^{-7} \mathrm{~m} / \mathrm{s}$, while the phase angle decrease $0.04 \mathrm{deg}$ from an initial value of $90 \mathrm{deg}$.

The similar pattern is occurred in the acceleration response. The acceleration magnitude rises gradually from $8.96 \times 10^{-11} \mathrm{~m} / \mathrm{s}^{2}$ to $9.3 \times 10^{-5} \mathrm{~m} / \mathrm{s}^{2}$, while the phase angle falls constantly $0.04 \mathrm{deg}$ from an initial value of $180 \mathrm{deg}$. The dynamic characteristics such as the steady state, overshoot and settling time in this case can be imposed by adjusting the parameter of the threshing drum that will influence the root locus position [18]. 

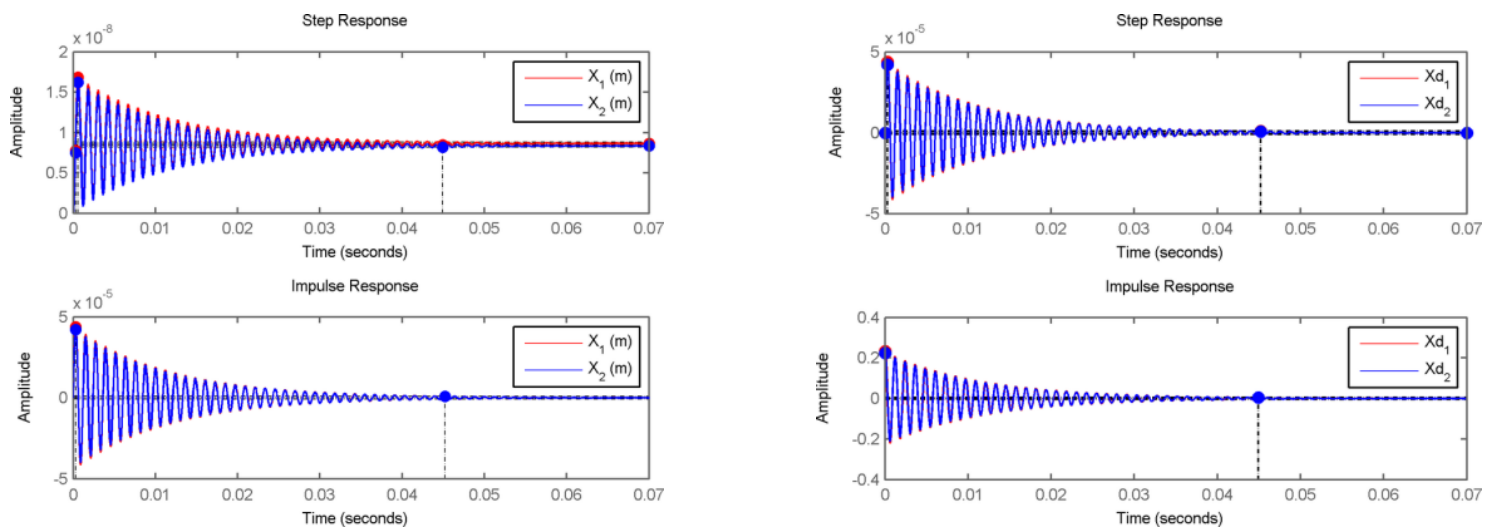

Impulse Response

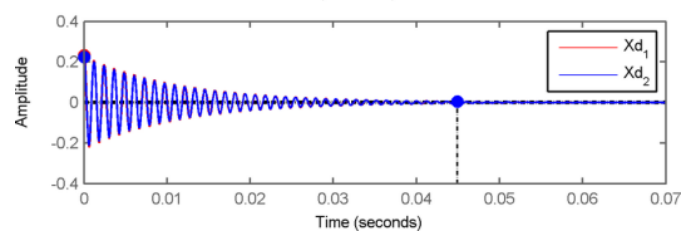

(a)

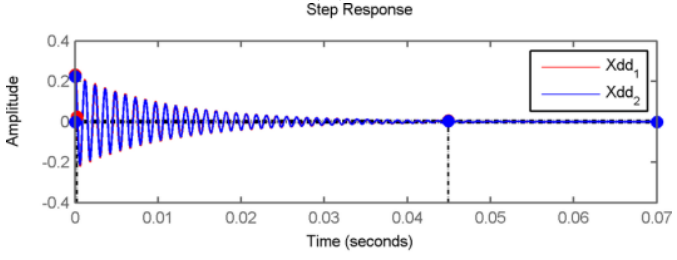

(b)

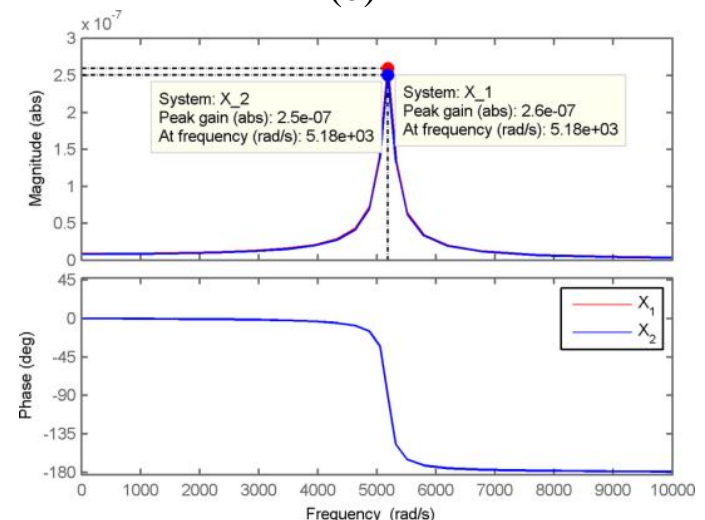

(d)

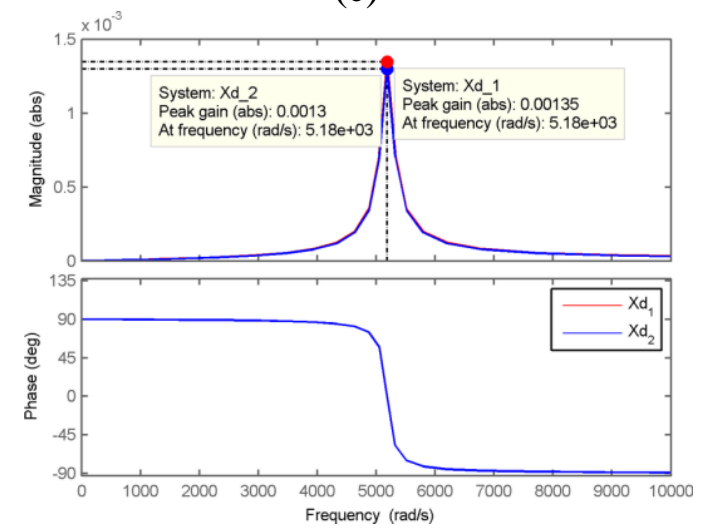

(e)

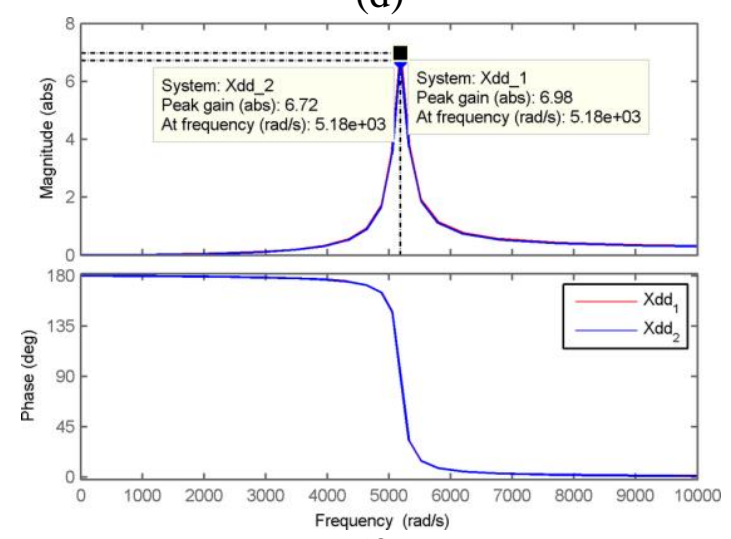

(f)

Figure 4. Time domain analysis of (a) Displacement, (b) Velocity, (c) Acceleration; and frequency domain analysis of (d) Displacement, (e) Velocity, (f) Acceleration

\section{Transmissibility}

In this case, the transmissibility is used to evaluate a vibration response transmitted to the ground or the main frame computed with reference to frequency function. Here the force transmissibility $(F T R)$ is defined as ratio of the transmitted force and the excitation force, while the displacement transmissibility $(D T R)$ is defined as ratio between displacement in point $1\left(x_{1}\right)$ and point $2\left(x_{2}\right)$ [19]. Those equations can be described as follows,

$$
F T R=\frac{F_{\text {Trans }}}{F_{E X}}=\frac{K_{E Q}\left(x_{1}-x_{2}\right)}{m r \omega^{2} \sin (\theta)}
$$




$$
D T R=\frac{x_{2}}{x_{1}}
$$

Figure 5(a) shows the force transmissibility simulated from Equation (9). At the natural frequency, the peak is gained at 30.1 with phase angle of $-87.1 \mathrm{deg}$. It means that the output amplitude $\left(F_{\text {Trans }}\right)$ is 30.1 times the input amplitude $\left(F_{E X}\right)$ and the output lags 89.1 deg behind the input. On the other hand, the displacement transmissibility, shown in Figure 5(b), has different characteristic compared with the force transmissibility. This peak is obtained at the beginning of the frequency of $0.000104 \mathrm{rad} / \mathrm{s}$. It can be seen that the magnitude is nearly constant and has small differences about 5 significant figures, while the phase angle are decayed from the starting point of $0 \mathrm{deg}$ to $-0.141 \mathrm{deg}$ in the end of frequency $10000 \mathrm{rad} / \mathrm{s}$. In the case of low frequency in the range of $100 \mathrm{rpm}$ $(10.5 \mathrm{rad} / \mathrm{s})$ to $1000 \mathrm{rpm}(104.7 \mathrm{rad} / \mathrm{s})$, both force and displacement transmissibility are nearly constant with has the magnitude of 1 and 0.9631 , respectively. It is because the square root of the ratio of the overall stiffness to the mass, that is considerably small, brings the natural frequency far away from working frequency which tends to produce low amplitude in the working frequency [14].

Next, vibration severity analysis, based on ISO 2372 adapted from Rao [14], is plotted in Figure 5(c) by taking Root Mean Square (RMS) of velocity in the threshing drum. In the working frequency range from $200 \mathrm{rpm}$ to $1000 \mathrm{rpm}$, the graph lies on "Good" criteria, which is in the range of $0.11 \mathrm{~mm} / \mathrm{s}$ to $2.8 \mathrm{~mm} / \mathrm{s}$. The result will be unsatisfactory when the threshing drum is set at the frequency of $1400 \mathrm{rpm}$ to $1600 \mathrm{rpm}$. Furthermore, impermissible vibration is occurred if only the velocity is larger than the upper bound of the unsatisfactory condition.

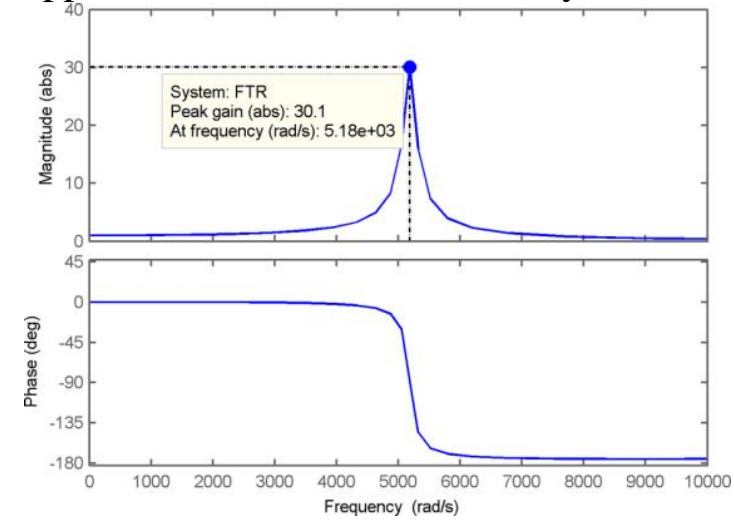

(a)

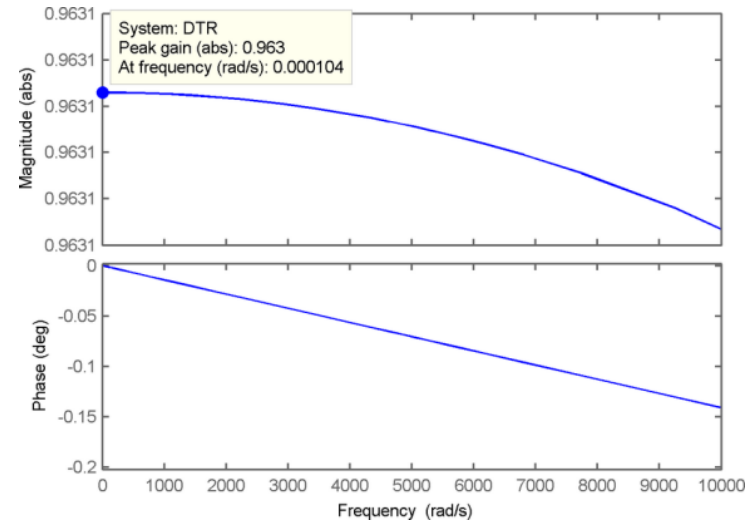

(b)

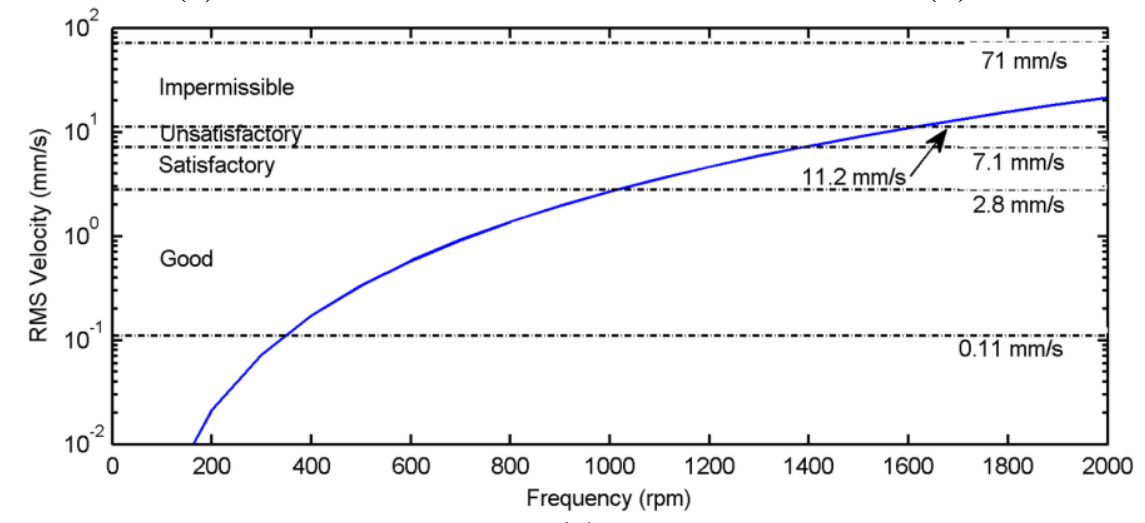

(c)

Figure 5. (a) Force transmissibility( $s$ ), (b) Displacement transmissibility, (c) RMS velocity of the threshing drum regarding ISO 2372 


\section{CONCLUSIONS}

The mathematical models of threshing drum, coupled with bearing in vertical mode, are derived and evaluated with transfer function analysis. In the vibration characteristic from the transfer function approach, the system has marginally stable while the responses of the threshing drum and the main bearing supports are similar in most cases. The system is less responsive in low frequency but much responsive in the high range of frequency obtained from transmissibility characteristics. The model does not take the effect of the threshing condition into account. However, the threshing condition can be linked with how the threshing drum reacts in zero state-response as discussed above. In the further study, a whole vibration of a power thresher can be obtained by means of combining the translational vibrations and torsional vibrations of the threshing drum with adding the stiffness of the main frame. The proposed design can satisfy in the industrial application engaged in the field of agricultural machinery in which the need of durability and reliability with less costs can be attained by minimizing the vibration.

\section{ACKNOWLEDGEMENTS}

This work is part of the project "IbM Kelompok Tani Desa Jenggawah Kecamatan Jenggawah Kabupaten Jember" which is funded by the Directorate for Research and Community Service - Directorate General of Research and Development Strengthening - Ministry of Research, Technology and Higher Education of the Republic of Indonesia (DRPM - RISTEKDIKTI) based on the decision No. 025/E3/2017.

\section{REFERENCES}

[1] Cacciola S, Agud IM, Bottasso CL. Detection of rotor imbalance, including root cause, severity and location. Journal of Physics: Conference Series. 2016;753:072003-8.

[2] Yamamoto GK, da Costa C, \& da Silva Sousa JS. A smart experimental setup for vibration measurement and imbalance fault detection in rotating machinery. Case Studies in Mechanical Systems and Signal Processing. 2016;4:8-18.

[3] Deng H, Diao Y, Zhang J, Zhang P, Ma M, Zhong X, Yu L. Three-dimensional identification for unbalanced mass of rotor systems in operation. Applied Sciences. 2018;8(2):173.

[4] Enginoglu O, Ozturk H. Active vibration reduction of rotating machinery using a new mass distribution control system design. Proceedings of the INTERNOISE 2016, 2016;InterNoise16:16864-874.

[5] Zhong T, Yaoming L, Zhenwei L. Optimal parameters prediction and control of rice threshing for longitudinal axial threshing apparatus. Transactions of the Chinese Society of Agricultural Engineering. 2016;32(22):70-76.

[6] Yang Y, Xie R, Liu Q. Design of a passive damper with tunable stiffness and its application in thin-walled part milling. The International Journal of Advanced Manufacturing Technology. 2016;89(9-12):2713-2720.

[7] Mohamad N, Yaakub J, Ab Maulod HE, Jeefferie AR, Yuhazri MY, Lau KT, Ahsan Q, Shueb MI, Othman R. Vibrational damping behaviors of graphene nanoplatelets reinforced NR/EPDM nanocomposites, Journal of Mechanical Engineering and Sciences. 2017; 11(4): 3274-3287.

[8] Tawi KB, Supriyo B, Ariyono S, Husain NA, Hamid ARA, Mazali II, Kob MSC. Design of electro-mechanical dual-acting pulley continuously variable 
transmission. Journal of Mechanical Engineering and Sciences, 2015; 8(1): 1332-1342.

[9] Kubas K. A model for the dynamic analysis of a belt transmission using the Dahl friction model. Journal of Theoretical and Applied Mechanics. 2017;55(4):1423-1435.

[10] Genta G, Genta A. "Road Vehicle Dynamics". 2017.

[11] Htay TT, Win HH, Win ZEE. Dynamics stiffness of shaft for thresher in combine harvester. International Journal of Mechanical and Production Engineering. 2015;3(7):140-144.

[12] Zeillinger R, Köttritsch H. Damping in a rolling bearing arrangement. Evolution, 1996;1996(1).

[13] Close CM, Frederick DH, Newell JC. "Modelling and Analysis of Dynamic Systems ( $3^{\text {rd }}$ ed)". 2002.

[14] Rao SS. "Mechanical Vibrations (6 ${ }^{\text {th }}$ ed)". 2017.

[15] Nise NN. "Control Systems Engineering ( $7^{\text {th }}$ ed)". 2015.

[16] Hallauer W. "Introduction to Linear, Time-Invariant, Dynamic Systems for Students of Engineering". 2016.

[17] Ab Latif N, Rus AZM. Vibration Transmissibility Study of High Density Solid Waste Biopolymer Foam. Journal of Mechanical Engineering and Sciences. 2014; 6(1):772-781.

[18] Schlarmann ME, Geiger RL. Relationship between amplifier settling time and pole-zero placements for second-order systems. Proceedings of the 43rd IEEE Midwest Symposium on Circuits and Systems. 2000;54-59.

[19] Yang J. Force transmissibility and vibration power flow behaviour of inerterbased vibration isolators. Journal of Physics: Conference Series. 2016;744:012234-9 